\title{
Interaction dam-reservoir: study of conservative and dissipative effects
}

\section{Interação barragem-reservatório: estudo dos efeitos conservativos e dissipativos}

S. F. DA SILVA

seleniofeio@yahoo.com.br https://orcid.org/0000-0003-1383-8163

L. J. PEDROSO

lineujp@gmail.com https://orcid.org/0000-0002-2734-3260

\begin{abstract}
In this paper, the Laplace's equation is solved analytically in the complex plane for the field of hydrodynamic pressures generated by the rigid body movement of a dam against a reservoir with infinite domain and incompressible fluid. The force the reservoir fluid exerts on the face of the dam is determined through the integration of the hydrodynamic pressure in the complex plane. The conservative effects (real part) and dissipative effects (imaginary part) of the force are analyzed as a function of the Froude number. The asymptotic solution of the aforementioned effects are also presented in this paper.
\end{abstract}

Keywords: dam-reservoir interaction, hydrodynamic pressure, equation of Laplace.

\section{Resumo}

Neste trabalho, a equação de Laplace é resolvida analiticamente no plano complexo para o campo de pressões hidrodinâmicas gerado pelo movimento de corpo rígido da barragem na presença de um meio fluido infinito e incompressível (um reservatório). A força exercida pelo fluido do reservatório na face da estrutura da barragem é então determinada através da integração da pressão hidrodinâmica no plano complexo, e os efeitos conservativos (parte real desta força) que traduzem os aspectos inerciais da interação barragem-reservatório, e os efeitos dissipativos (parte imaginária desta força) que traduzem os aspectos de amortecimento desta interação são analisados em função de um parâmetro escalar característico de fluxo de superfície livre (número de Froude). É feita, também, a apresentação das soluções assintóticas para os efeitos citados.

Palavras-chave: interação barragem-reservatório, pressão hidrodinâmica, equação de Laplace. 


\section{Introduction}

Westergaard [18] not considering the effect of free surface waves, developed an exact analytical series solution for the Laplace equation that represents the problem illustrated in Figure 1. Even without considering the effects of free surface waves, the work performed by Sharan [14] and Kuçükarslan [7] using the Finite Element Method. Silva \& Pedroso [15] and Silva [16], using the Variable Separation Technique, presented solutions for the Laplace equation using a truncation surface at a distance from structure in the infinite domain of an incompressible fluid.

Azevedo [2] used the Boundary Element Method to study the propagation of surface waves. Trindade [17] continued the work of Azevedo by adding an apparatus for the generation and propagation of waves in experimental channels using piston actuators and flap actuators.

The wave attenuation problem at the far-end of the reservoir has also been studied by Gogoi et al. [6]; Parrinello et al. [11]; Li [9]; Bouaanani et al. [3]; Aydin et al. [1]; and Mendes [10].

This paper presents an analytical study of the Laplace equation in the field of complex numbers. Through the linearization of the free surface boundary condition with gravity waves, the field of hydrodynamic pressures, in the complex form, generated by the rigid body movement of the dam, is determined. Also, the conservative and dissipative effects of the force acting on the face of the dam structure as a function of the free surface wave dissipation are also determined, considering its non-reflection condition at far end, as shown in the dam-reservoir interaction scheme shown in Figure 1.

\section{Analytical formulation for the hydrodynamic pressure in the complex plane}

Considering the incompressible and non-viscous fluid, the hydro- dynamic pressure in the reservoir resulting from the movement of a submerged structure satisfies the Laplace equation (Lamb [8]):

$\frac{\partial^{2} p}{\partial x^{2}}+\frac{\partial^{2} p}{\partial y^{2}}=0$

Boundary conditions are based on the following additional assumptions:

a) The domain of the fluid extends far boundary and its motion is two-dimensional.

b) The fluid-structure interface is vertical.

c) The submerged structure is rigid, its height is not less than the depth of the fluid, the structure vibrates in the normal direction of the fluid-structure interface.

d) The bottom of the fluid domain is rigid and horizontal.

Considering also the effects of surface waves, and their non-reflection at infinity, the following boundary conditions are obtained:

i) At the bottom of the reservoir $(y=0): \frac{\partial p}{\partial y}=0$ (hard bottom).

ii) On the free surface $(y=H): \frac{\partial p}{\partial y}=\frac{\omega^{2}}{g} p$ (linearized and in the frequency domain).

iii) On the fluid-structure interface $(x=0): \frac{\partial p}{\partial x}=-\rho_{f} V_{g}=\rho_{f} \omega^{2} X$ (linear pressure).

iv) Infinite Domain Reservoir $(x \rightarrow \infty): p=0$ (non-reflection at far end of free surface waves).

The parameter $V_{g}$ corresponds to the amplitude of the acceleration in the base of the dam that is excited with an harmonic movement of translation with amplitude $X$ and frequency $\omega$. The fluid movement is assumed to occur in the dam-reservoir plane and $\mathrm{g}$ corresponds to the acceleration of gravity.

Let be the expression for the field of hydrodynamic pressures $p(x, y)$ sought. Applying the separation of variables technique, see Chakrabarti and Chopra [4], we have:

$\frac{F^{\prime \prime}}{F}=-\frac{G^{\prime \prime}}{G}=K^{2} \quad \therefore\left\{\begin{array}{l}G^{\prime \prime}+K^{2} G=0 \\ F^{\prime \prime}-K^{2} F=0\end{array}\right.$
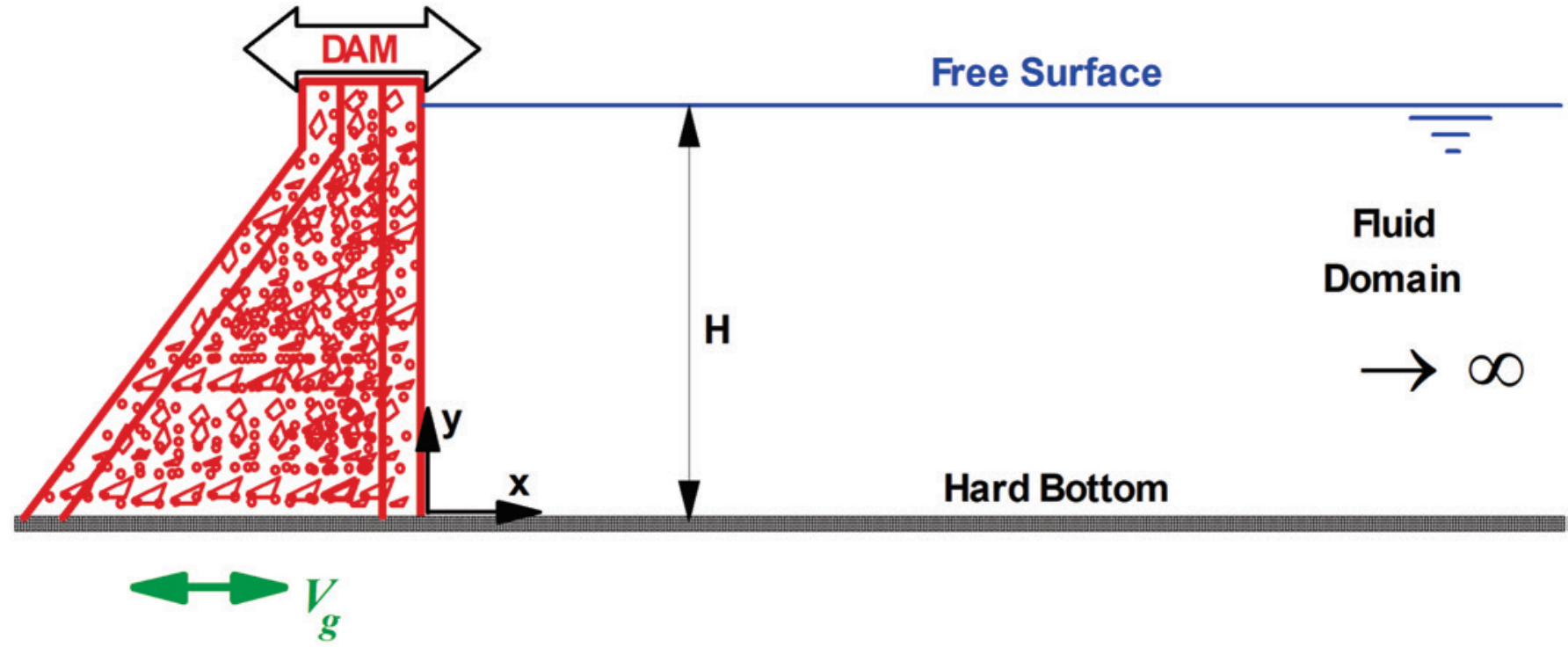

Figure 1

Scheme of the dam-reservoir interaction 
For the equation: $G^{\prime \prime}+K^{2} G=0 \quad \therefore \frac{\partial^{2} G}{\partial y^{2}}+K^{2} G=0$ $\mathrm{a}-\mathrm{In}$ the $\mathrm{y}$ direction, if $\mathrm{K}$ is real, we find:

$G_{n}(y)=B_{n} \cos \left(k_{n} y\right)$

Using the boundary condition $\frac{\partial}{\partial y} p(x, y) \mid y=H=\frac{\omega^{2}}{g} p$, we have:

$F(x)\left[-B_{n} k_{n} \sin \left(k_{n} H\right)\right]=\frac{\omega^{2}}{g} F(x)\left[B_{n} \cos \left(k_{n} H\right)\right]$

Like this:

$-\left(k_{n} H\right) \operatorname{tg}\left(k_{n} H\right)=\frac{\omega^{2} H}{g}$

$\mathrm{b}-$ In the $\mathrm{y}$ direction, if $\mathrm{K}$ is imaginary, we find for the solution $i \mathrm{k}_{0}$ (with $\mathrm{k}_{0}$ real):

$G_{0}(y)=B_{0} \cosh \left(k_{0} y\right)$

Using the boundary condition: $i i) \frac{\partial}{\partial y} p(x, y) \mid y=H=\frac{\omega^{2}}{g} p$, we have:

$F(x)\left[B_{0} k_{0} \sin \left(k_{0} H\right)\right]=\frac{\omega^{2}}{g} F(x)\left[B_{0} \cos \left(k_{0} H\right)\right]$

Thus:

$\left(k_{0} H\right) \operatorname{tgh}\left(k_{0} H\right)=\frac{\omega^{2} H}{g}$

For the equation $F^{\prime \prime}-K^{2} F=0 \quad \therefore \frac{\partial^{2} F}{\partial x^{2}}-K^{2} F=0$ :
$\mathrm{a}-\mathrm{In}$ the $\mathrm{x}$ direction, if $\mathrm{K}$ is real, we find:

$F(x)=C_{1} e^{k x}+C_{2} e^{-k x}$

Using the boundary condition iv) $p(x, y) \mid x=\infty=0$, we obtain:

$F_{n}(x)=C_{n} e^{-k_{n} x}$.

(3) Using the boundary condition iii) $\frac{\partial}{\partial x} p(x, y) \mid x=0=-\rho_{f} V_{g}$, in $P_{n}(x, y)=G_{n}(y) F_{n}(x)$, results: $C_{n}=\rho_{f} V_{g} \frac{1}{k_{n}} \frac{\int_{0}^{H} G_{n}(y) d y}{\int_{0}^{H} G_{n}^{2}(y) d y}$.

Therefore:

$F_{n}(x)=\rho_{f} V_{g} \frac{\alpha_{n}}{k_{n}} e^{-k_{n} x}$, with $\alpha_{n}=\frac{\int_{0}^{H} G_{n}(y) d y}{\int_{0}^{H} G_{n}^{2}(y) d y}$

$\mathrm{b}$ - In the $\mathrm{x}$-direction, if $\mathrm{K}$ is imaginary, we find for the solution $\mathrm{ik}_{0}$ (with $\mathrm{k}_{0}$ real):

$F(x)=C_{1} e^{i k_{0} x}+C_{2} e^{-i k_{0} x}$. Using the boundary conditions:

iv) $p_{g}(x, y) \mid x=\infty=0$, we have: $F_{0}(x)=C_{0} e^{-i k_{0} x}$, and

iii) $\frac{\partial}{\partial x} p(x, y) \mid x=0=-\rho_{f} V_{g}$, in

$$
P_{0}(x, y)=G_{0}(y) F_{0}(x) \rightarrow C_{0}=\rho_{f} V_{g} \frac{1}{i k_{0}} \frac{\int_{0}^{H} G_{0}(y) d y}{\int_{0}^{H} G_{0}^{2}(y) d y} .
$$

Like this:

$F_{0}(x)=-i \rho_{f} V_{g} \frac{\alpha_{0}}{k_{0}} e^{-i k_{0} x} ;$ with $\alpha_{0}=\frac{\int_{0}^{H} G_{0}(y) d y}{\int_{0}^{H} G_{0}^{2}(y) d y}$

With Equation 3 and Equation 7, we obtain:

$P_{n}(x, y)=\rho_{f} V_{g} \sum_{n=1}^{\infty} \frac{B_{n} \alpha_{n}}{k_{n}} e^{-k_{n} x} \cos \left(k_{n} y\right)$

\section{Table 1}

Determination of parameters involved in hydrodynamic force

\begin{tabular}{|c|c|c|c|c|}
\hline $\begin{array}{l}\begin{array}{c}\text { Froude number } \\
\text { squared }\end{array} \\
F_{r}^{2}=\frac{\omega^{2} H}{g}\end{array}$ & $\begin{array}{l}\text { Argument of } \\
\text { the real part } \\
\qquad\left(k_{n} H\right)\end{array}$ & $\begin{array}{l}\text { Argument of the } \\
\text { imaginary part } \\
\left(k_{0} H\right)\end{array}$ & $\begin{array}{c}\text { Conservative } \\
\text { part } \\
\delta\end{array}$ & $\begin{array}{c}\text { Dissipative } \\
\text { part } \\
\beta\end{array}$ \\
\hline $10^{-1} \equiv 0.1$ & 3.1094 & 0.3216 & 0.0001 & 3.1087 \\
\hline 0.2 & 3.0767 & 0.4627 & 0.0003 & 2.1591 \\
\hline 0.3 & 3.0433 & 0.5767 & 0.0007 & 1.7300 \\
\hline 0.4 & 3.0095 & 0.6778 & 0.0013 & 1.4690 \\
\hline 0.5 & 2.9751 & 0.7717 & 0.0022 & 1.2868 \\
\hline 0.6 & 2.9403 & 0.8611 & 0.0034 & 1.1490 \\
\hline 0.7 & 2.9051 & 0.9476 & 0.0049 & 1.0395 \\
\hline 0.8 & 2.8697 & 1.0324 & 0.0067 & 0.9488 \\
\hline 0.9 & 2.8341 & 1.1163 & 0.0090 & 0.8717 \\
\hline $10^{\circ} \equiv 1.0$ & 2.7984 & 1.1997 & 0.0117 & 0.8048 \\
\hline 2 & 2.4587 & 2.0653 & 0.0669 & 0.4008 \\
\hline 3 & 2.2045 & 3.0145 & 0.1547 & 0.2129 \\
\hline 4 & 2.0430 & 4.0027 & 0.2320 & 0.1241 \\
\hline 5 & 1.9411 & 5.0005 & 0.2876 & 0.0799 \\
\hline 6 & 1.8734 & 6.0001 & 0.3268 & 0.0555 \\
\hline 7 & 1.8260 & 7.0000 & 0.3551 & 0.0408 \\
\hline 8 & 1.7910 & 8.0000 & 0.3763 & 0.0312 \\
\hline 9 & 1.7644 & 9.0000 & 0.3927 & 0.0247 \\
\hline $10^{1} \equiv 10$ & 1.7434 & 10.0000 & 0.4057 & 0.0200 \\
\hline$* 3.3$ & 2.1478 & 3.3088 & 0.1800 & 0.1800 \\
\hline
\end{tabular}

* Point of intersection of the curve of the real part with the curve of the imaginary part, see Figure 2 . 


\section{Table 2}

Numeric values for $\delta$ and $\beta$

\begin{tabular}{|c|c|c|c|c|c|c|c|}
\hline \multirow{2}{*}{$F_{r}^{2}=\frac{\omega^{2} H}{g}$} & \multirow{2}{*}{$\mathfrak{J}=\frac{1}{F_{r}^{2}}$} & \multicolumn{3}{|c|}{$\delta$} & \multicolumn{3}{|c|}{$\beta$} \\
\hline & & Exact & Asymptotic & $\begin{array}{l}\text { Relative error } \\
(\%)\end{array}$ & Exact & Asymptotic & $\begin{array}{c}\text { Relative error } \\
(\%)\end{array}$ \\
\hline 1 & 1 & 0.0117 & 0.5428 & 4539 & 0.8048 & 2.0000 & 147 \\
\hline 5 & 0.2 & 0.2876 & 0.5428 & 89 & 0.0799 & 0.0800 & 0.13 \\
\hline 10 & 0.1 & 0.4057 & 0.5428 & 33 & 0.0200 & 0.0200 & 0.00 \\
\hline
\end{tabular}

With Equation 5 and Equation 8, we get:

$P_{0}(x, y)=-i \rho_{f} V_{g} \frac{B_{0} \alpha_{0}}{k_{0}} e^{-i k_{0} x} \cosh \left(k_{0} y\right)$

In a general representation in the complex plane:

$p(z)=\rho_{f} V_{g}\left[\sum_{n=1}^{\infty} \frac{B_{n} \alpha_{n}}{k_{n}} e^{-k_{n} x} \cos \left(k_{n} y\right)-i \frac{B_{0} \alpha_{0}}{k_{0}} e^{-i k_{0} x} \cosh \left(k_{0} y\right)\right]$

The Equation 11 corresponds to the analytical expression for the hydrodynamic pressure calculation in the complex plane. Once the expression for the hydrodynamic pressure field in the complex plane, Equation 11, is established, the force exerted by the fluid on the face of the structure is:

$F(z)=-\int_{0}^{H} P(0, y) d y$

$=-\int_{0}^{H} \rho_{f} V_{g}\left[\sum_{n=1}^{\infty} \frac{B_{n} \alpha_{n}}{k_{n}} e^{-k_{n} 0} \cos \left(k_{n} y\right)-i \frac{B_{0} \alpha_{0}}{k_{0}} e^{-i k_{0} 0} \cosh \left(k_{0} y\right)\right] d y$

With:

$\frac{B_{n} \alpha_{n}}{k_{n}}=\frac{B_{n}}{k_{n}} \frac{\int_{0}^{H} G_{n}(y) d y}{\int_{0}^{H} G_{n}^{2}(y) d y}=\frac{B_{n}}{k_{n}} \frac{\int_{0}^{H} B_{n} \cos \left(k_{n} y\right) d y}{\int_{0}^{H} B_{n}^{2} \cos ^{2}\left(k_{n} y\right) d y}=\frac{1}{k_{n}} \frac{2 \operatorname{sen}\left(k_{n} H\right)}{\cos \left(k_{n} H\right) \operatorname{sen}\left(k_{n} H\right)+k_{n} H}$

$\frac{B_{0} \alpha_{0}}{k_{0}}=\frac{B_{0}}{k_{0}} \frac{\int_{0}^{H} G_{0}^{H}(y) d y}{\int_{0}^{H}(y) d y}=\frac{B_{0}}{k_{0}} \frac{\int_{0}^{H} B_{0} \cosh \left(k_{0} y\right) d y}{\int_{0}^{H} B_{0}^{2} \cosh ^{2}\left(k_{0} y\right) d y}=\frac{1}{k_{0}} \frac{2 \operatorname{senh}\left(k_{0} H\right)}{\cosh \left(k_{0} H\right) \operatorname{senh}\left(k_{0} H\right)+k_{0} H}$

Therefore:

$F(z)=-\rho_{f} V_{g} H^{2}\left[\sum_{n=1}^{\infty} \frac{2 \operatorname{sen}^{2}\left(k_{n} H\right)}{\left(k_{n} H\right)^{3}\left(1+\frac{\operatorname{sen}\left(2 k_{n} H\right)}{2 k_{n} H}\right)}-i \frac{2 \operatorname{senh}^{2}\left(k_{0} H\right)}{\left(k_{0} H\right)^{3}\left(1+\frac{\operatorname{senh}\left(2 k_{0} H\right)}{2 k_{0} H}\right)}\right]$

$F_{0}(z)=\frac{F(z)}{-\rho_{f} V_{g} H^{2}}=\left[\sum_{n=1}^{\infty} \frac{2 \operatorname{sen}^{2}\left(k_{n} H\right)}{\left(k_{n} H\right)^{3}\left(1+\frac{\operatorname{sen}\left(2 k_{n} H\right)}{2 k_{n} H}\right)}-i \frac{2 \operatorname{senh}^{2}\left(k_{0} H\right)}{\left(k_{0} H\right)^{3}\left(1+\frac{\operatorname{senh}^{2}\left(2 k_{0} H\right)}{2 k_{0} H}\right)}\right]$

The Equation 12 corresponds to the analytical expression of the dimensionless hydrodynamic force along the face of the dam in the complex plane.

\section{Analysis and graphical representation of results}

The real part of the coefficient $F_{0}(Z)$ presented in Equation 12 will be represented by $\delta$, and the imaginary part of this coefficient will be represented by $\beta$, which correspond respectively to the conservative part and the dissipative part of the effect of the fluid on the structure (Gibert [5]). The terms $\delta$ and $\beta$ are functions of the

parameter $\frac{\omega^{2} H}{}$, according to the transcendental Equation 4 and Equation 6 , respectively.
The parameter $\frac{\omega^{2} H}{g}$ involved in the transcendental equations is known as the "Froude number", and expresses the importance of the forces of gravity in relation to the forces of inertia of the fluid (Sancho [13]):

$F_{r}=\frac{\text { Force }_{\text {inertia }}}{\text { Force } \text { gravity }} \propto \frac{\rho L^{2} U^{2}}{\rho g L^{3}} \Rightarrow F_{r}=\frac{U}{\sqrt{g L}}$

Where $U$ is a characteristic velocity of the global flow field, $g$ is the acceleration of gravity, and $L$ is a characteristic length of the structure exposed to the flow.

The Froude number can also be considered as the relation between fluid velocity and surface wave velocity, with small disturbance propagation speed $(c=\sqrt{g H})$, where $\mathrm{H}$ is the depth of the reservoir. The term "Froude number" honors the English engineer William Froude (18101879), who presented this parameter conducting tests in the investigation of the resistance of ship hulls with the use of models (Pedroso [12]). According to Sancho [13], the Froude number can classify the flow regime in:

$\mathrm{Fr}<1$ slow regime: disturbances propagate upstream and downstream.

$\mathrm{Fr}>1$ fast regime: disturbances propagate downstream.

In the case under study, for the harmonic motion of the wave we have $U=\frac{2 \pi}{T} H=\omega H$, with $\mathrm{T}$ and $\omega$ corresponding to the period and frequency of the wave, respectively. The Froude number can then be presented as follows (Gibert [5]):

$F_{r}=\frac{U}{\sqrt{g H}}=\frac{\omega H}{\sqrt{g H}} \Rightarrow F_{r}^{2}=\frac{\omega^{2} H^{2}}{g H} \quad \therefore F_{r}^{2}=\frac{\omega^{2} H}{g}$

Therefore, by using Equation 4, Equation 6, Equation 12 and Equation 14, the Table 1 and Table 2 are formed. The data in Table 1 and the graphical representation of Figure 2 show the evolution of the real part $(\delta)$ and the imaginary part $(\beta)$ as a function of the square of the Froude number.

The intersection point of the curves in the graph of Figure 2 is shown in Table 1. This point cannot be determined analytically by the conventional process of a system of two simultaneous equations.

\subsection{Asymptotical solutions}

For the analysis of extreme situations (limits) of the Froude number $\left(F_{r}^{2}=\frac{\omega^{2} H}{g}\right)$ in the transcendental equations, a new parameter $(\mathfrak{I})$ is defined as: $\mathfrak{I}=\frac{1}{F_{r}^{2}}$. It is observed that: 


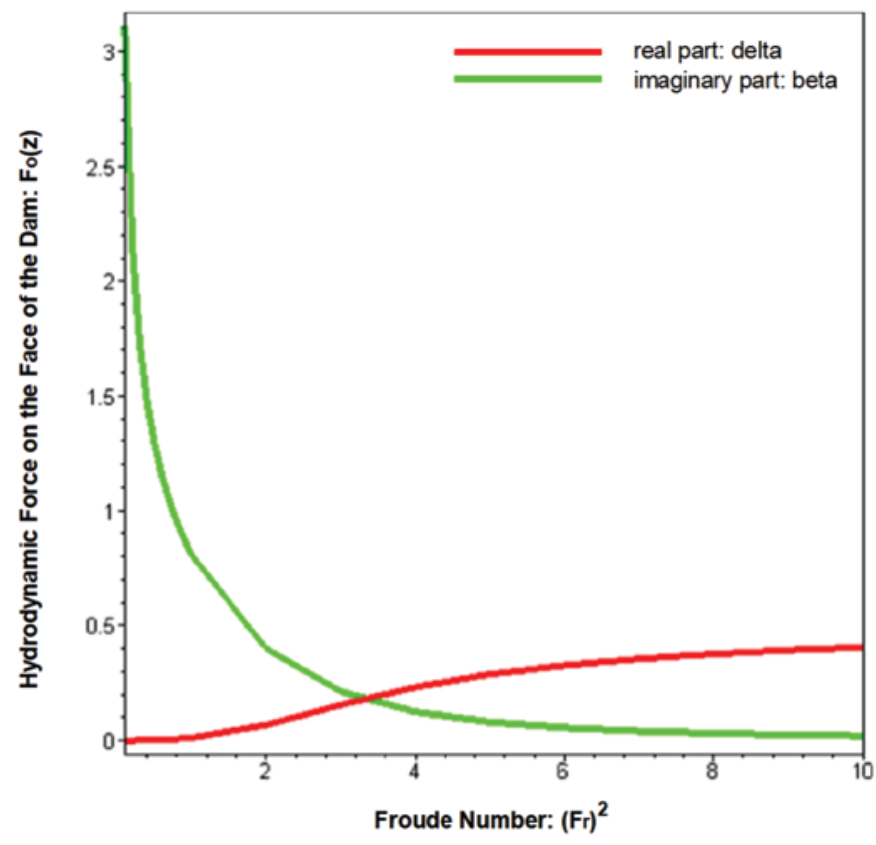

\section{Figure 2}

Real (conservative) and imaginary (dissipative) part of the fluid force on the structure

a) For $\mathfrak{I}$ « 1 :

a.1) The Equation 4 can be written as:

$-\left(k_{n} H\right) \operatorname{tg}\left(k_{n} H\right)=\frac{\omega^{2} H}{g}=\frac{1}{\mathfrak{J}}$

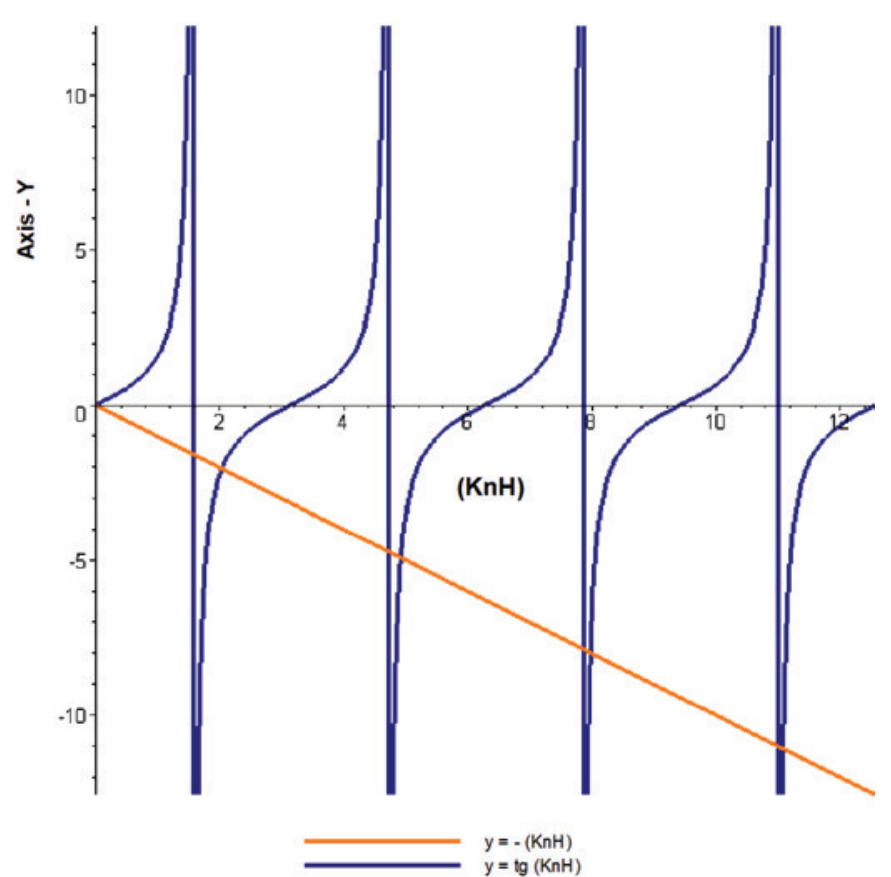

Figure 3

Graph of the transcendental equation corresponding to equation 15
The Figure 3 represents the graph of the transcendental equation corresponding to Equation 15.

From the graph in Figure 3:

$\mathfrak{I} \rightarrow 0 \Rightarrow \frac{1}{\mathfrak{J}} \rightarrow \infty \Rightarrow k_{n} H \cong(2 n-1) \frac{\pi}{2}$.

Replacing this argument in the real part of Equation 12, we have:

$\delta \cong \frac{16}{\pi^{3}} \sum_{n=1}^{\infty} \frac{1}{(2 n-1)^{3}} \therefore \delta \cong 0.5428$.

The conservative part $(\delta)$ corresponds to an additional mass effect (Gibert [5]) which can be calculated by imposing zero pressure on the free surface as a boundary condition.

a.2) The Equation 6 can be written as:

$+\left(k_{0} H\right) \operatorname{tgh}\left(k_{0} H\right)=\frac{\omega^{2} H}{g}=\frac{1}{\mathfrak{J}}$

The Figure 4 represents the graph of the transcendental equation corresponding to Equation 16. The Equation 16 can be written as follows: $\left(k_{0} H\right) \mathfrak{I}=\frac{1}{\operatorname{tgh}\left(k_{0} H\right)} ; \mathfrak{I}$ is inversely proportional to $\operatorname{tgh}\left(k_{0} H\right)$, so for a $\mathfrak{I}$ minimal $\operatorname{tgh}\left(k_{0} H\right)$, it will have its maximum value, which is equal to $\left(\left.\operatorname{tgh}\left(k_{0} H\right)\right|_{\max }\right)$, see Figure 4 , resulting in $\left(k_{0} H\right) \cong \frac{1}{\mathfrak{J}}$. Replacing these asymptotic results in $\beta$, we find:

$\beta \cong \frac{2}{\left(\frac{1}{\mathfrak{J}}\right)^{2}} \frac{(1)^{2}}{\left(\left(\frac{1}{\mathfrak{I}}\right) 0^{2}+1\right)}=\frac{2}{\left(\frac{1}{\mathfrak{J}}\right)^{2}} 1 \quad \therefore \beta \cong 2 \mathfrak{J}^{2}$.

In this case, the dissipative part $(\beta)$ is small.

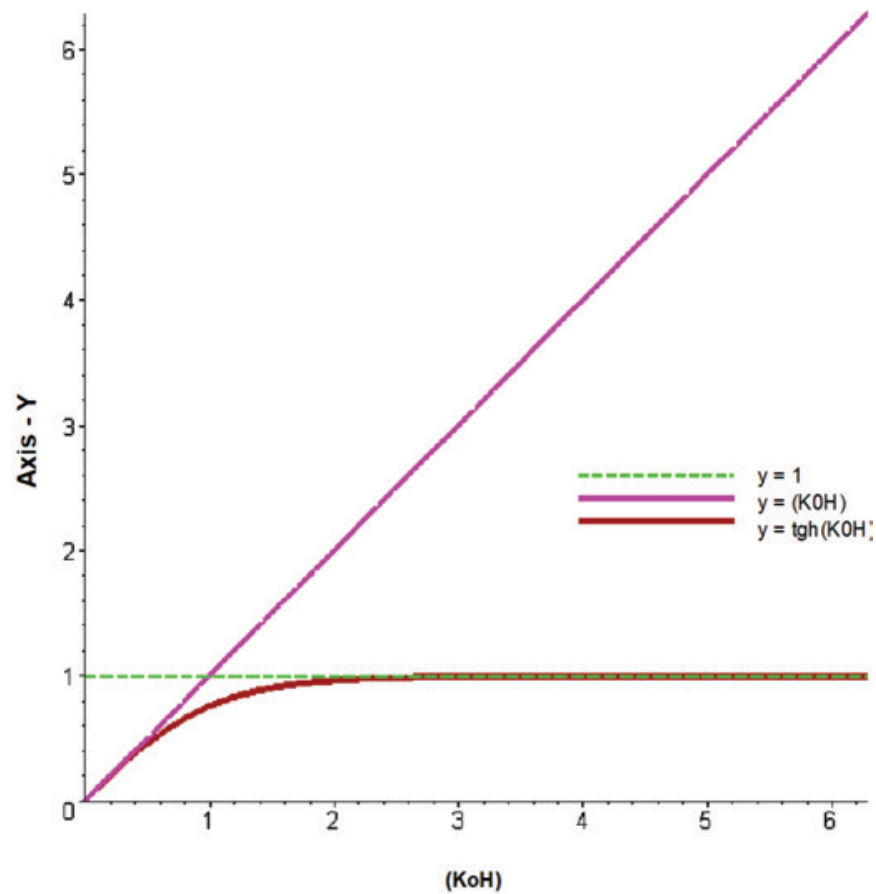

Figure 4

Graph of the transcendental equation corresponding to equation 16 


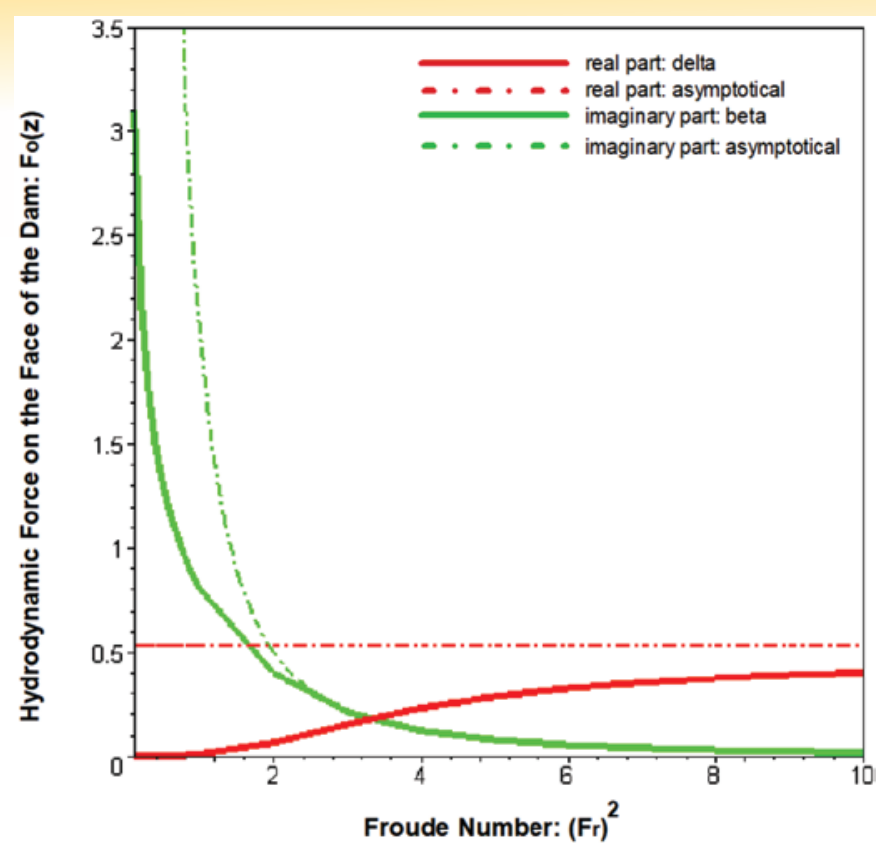

Figure 5

Exact and asymptotic curves ( $\mathfrak{I}$ « 1 ) for real and imaginary part of Table 2

In summary, for $\mathfrak{I}$ «1 (fast scheme):

$\left\{\begin{array}{c}k_{n} H \cong(2 n-1) \frac{\pi}{2} \\ \left(k_{0} H\right) \cong \frac{1}{\mathfrak{J}}\end{array} \Rightarrow\left\{\begin{array}{c}\delta \cong 0.5428 \\ \beta \cong 2 \mathfrak{J}^{2}\end{array}\right.\right.$

In order to verify these results, numerical values for $\delta$ and $\beta$, calculated by both the exact expressions and the asymptotic expressions, are presented in Table 2.

It is observed that with the increase of the Froude number the percentage relative error decreases, that is: asymptotic solutions are close to the exact solutions. The graphs of Figure 5, corresponding to Table 2, illustrate these convergences.

b) For $\mathfrak{I} » 1$ :

b. 1) From the graph of Figure 3:

$\mathfrak{I} \rightarrow \infty \Rightarrow \frac{1}{\mathfrak{J}} \rightarrow 0 \Rightarrow k_{n} H \cong n \pi-\frac{1}{\mathfrak{I} n \pi}$.

Substituting this argument into the real part of Equation 12 and using the trigonometry arcs addition properties:

$\delta \cong \frac{1}{\mathfrak{J}^{2}} \frac{2}{\pi^{5}} \sum_{n=1}^{\infty} \frac{1}{n^{5}} \quad \therefore \delta \cong 0.0068 \frac{1}{\mathfrak{J}^{2}}$.

b.2) In Equation 16, $\Im$ is inversely proportional to $\operatorname{tgh}\left(\mathrm{k}_{0} \mathrm{H}\right)$, so for a maximum $\mathfrak{I}, \operatorname{tgh}\left(\mathrm{k}_{0} \mathrm{H}\right)$, it will have a small value and approximately equal to its own argument $\operatorname{tgh}\left(\mathrm{k}_{0} \mathrm{H}\right) \cong\left(\mathrm{k}_{0} \mathrm{H}\right)$, see Figure 4. It results then: $\left(k_{0} H\right) \cong \frac{1}{\sqrt{\mathfrak{I}}}$. The imaginary part of Equation 12 can be presented as follows:

\section{Table 3}

Numeric values for $\delta$ and $\beta$ $\beta \cong \frac{2}{\left(\frac{1}{\sqrt{\mathfrak{I}}}\right)^{2}} \frac{\left(\frac{1}{\sqrt{\mathfrak{I}}}\right)^{2}}{\left(\left(\frac{1}{\sqrt{\mathfrak{I}}}\right) 1^{2}+\frac{1}{\sqrt{\mathfrak{I}}}\right)}=\frac{2}{\left(\frac{2}{\sqrt{\mathfrak{I}}}\right)} \quad \therefore \beta \cong \sqrt{\mathfrak{I}}$

In this case, the behavior is singular because the free surface condition for $\mathfrak{I}$ » 1 is close of a flow node, the fluid is then confined between two nearly fixed horizontal surfaces (Gibert [5]).

In summary, for $\mathfrak{I}$ » 1 (slow regime):

$\left\{\begin{array}{c}k_{n} H \cong n \pi-\frac{1}{\mathfrak{I} n \pi} \\ \left(k_{0} H\right) \cong \frac{1}{\sqrt{\mathfrak{I}}}\end{array} \Rightarrow\left\{\begin{array}{c}\delta \cong 0.0068 \frac{1}{\mathfrak{I}^{2}} \\ \beta \cong \sqrt{\mathfrak{I}}\end{array}\right.\right.$

In order to verify these results, numerical values for $\delta$ and $\beta$ are presented in Table 3 calculated by the exact expressions and the asymptotic expressions.

It is observed that with the decrease of the Froude number, the percentage relative error decreases, that is, the asymptotic solutions approximate the exact solutions. The graphs in Figure 6 illustrate these convergences.

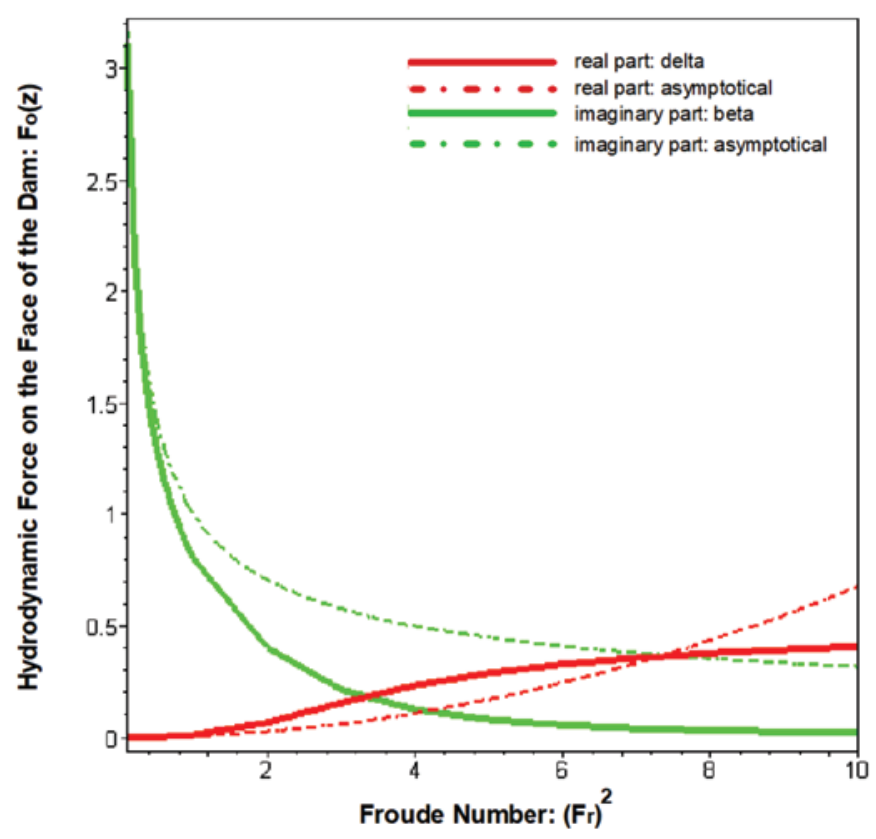

Figure 6

Exact and asymptotic curves ( $\mathfrak{I} » 1)$ for real and imaginary part of Table 3

\begin{tabular}{ccccccccc}
\hline$F_{r}^{2}=\frac{\omega^{2} H}{g}$ & $\mathfrak{J}=\frac{1}{F_{r}^{2}}$ & & Exact & Asymptotic & $\begin{array}{c}\text { Relative error } \\
\text { (\%) }\end{array}$ & Exact & $\begin{array}{c}\text { Asymptotic } \\
\text { Relative error } \\
(\%)\end{array}$ \\
\hline 1 & 1 & 0.0117 & 0.0068 & 42 & 0.8048 & 1.0000 & 24 \\
0.2 & 5 & 0.0003 & 0.0003 & 0 & 2.1591 & 2.2361 & 3.57 \\
0.1 & 10 & 0.0001 & 0.0001 & 0 & 3.1087 & 3.1623 & 1.72 \\
\hline
\end{tabular}


Next, graphs of the magnitude and phase angle of the dimensionless hydrodynamic force on the face of the dam are presented as a function of the Froude number (Figure 7 and Figure 8). The magnitude and phase angle of a complex function, defined below, depend on the real part and the imaginary part of it. As previously seen, the following results are obtained for these parameters:

1) Exact solution:

$(\delta, \beta)=\left(\sum_{n=1}^{\infty} \frac{2 \operatorname{sen}^{2}\left(k_{n} H\right)}{\left(k_{n} H\right)^{3}\left(1+\frac{\operatorname{sen}\left(2 k_{n} H\right)}{2 k_{n} H}\right)}, \frac{2 \operatorname{senh}^{2}\left(k_{0} H\right)}{\left(k_{0} H\right)^{3}\left(1+\frac{\operatorname{senh}\left(2 k_{0} H\right)}{2 k_{0} H}\right)}\right)$

2) Asymptotic solutions:

a) to small Froude numbers: $(\delta, \beta) \cong\left(0.0068 F_{r}^{2}, \frac{1}{\sqrt{F_{r}}}\right)$

b) to large Froude numbers: $(\delta, \beta) \cong\left(0.54, \frac{2}{F_{r}^{2}}\right)$

The magnitude and phase angle of a complex function are respectively defined as: $|r|=\sqrt{\delta^{2}+\beta^{2}}$ and $\theta=\operatorname{arctg}\left(\frac{\beta}{\delta}\right)$. Working with the exact solution and the asymptotic solutions, the graphs are generated in Figure 7 and Figure 8.

\section{Conclusions}

From the results obtained in this study, some comments and conclusions can be evidenced:

1) The separation of variables technique, for the analytical solution of the proposed Laplace equation, for hydrodynamic pressure analysis in the plane of complex numbers

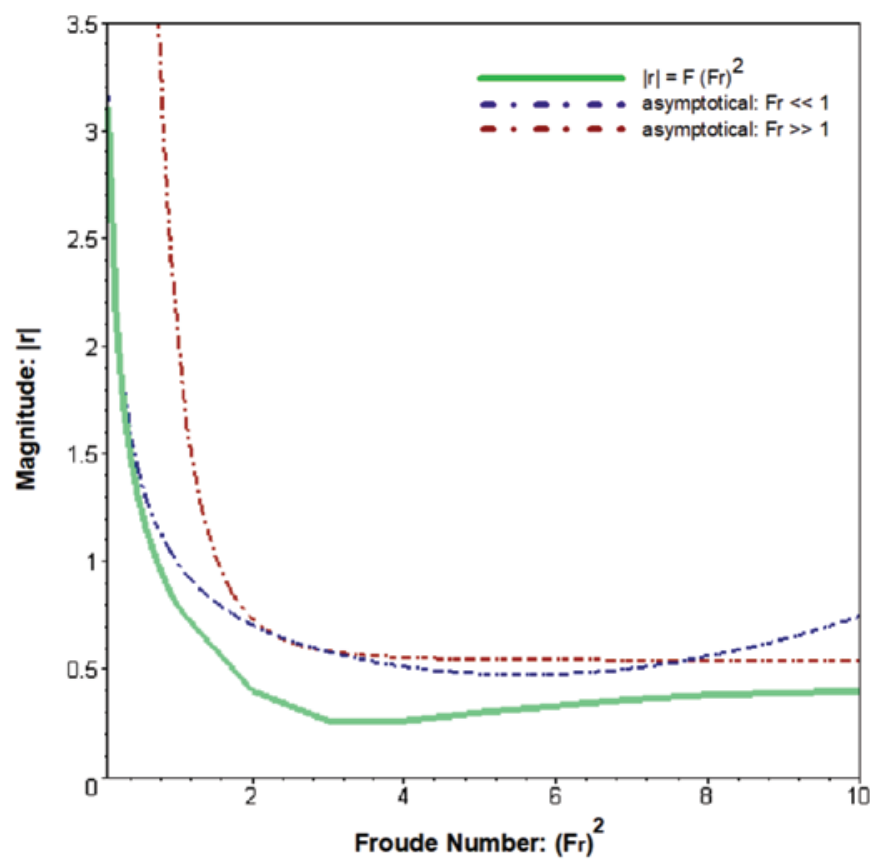

\section{Figure 7}

Magnitude of the dimensionless hydrodynamic force on the face of the dam

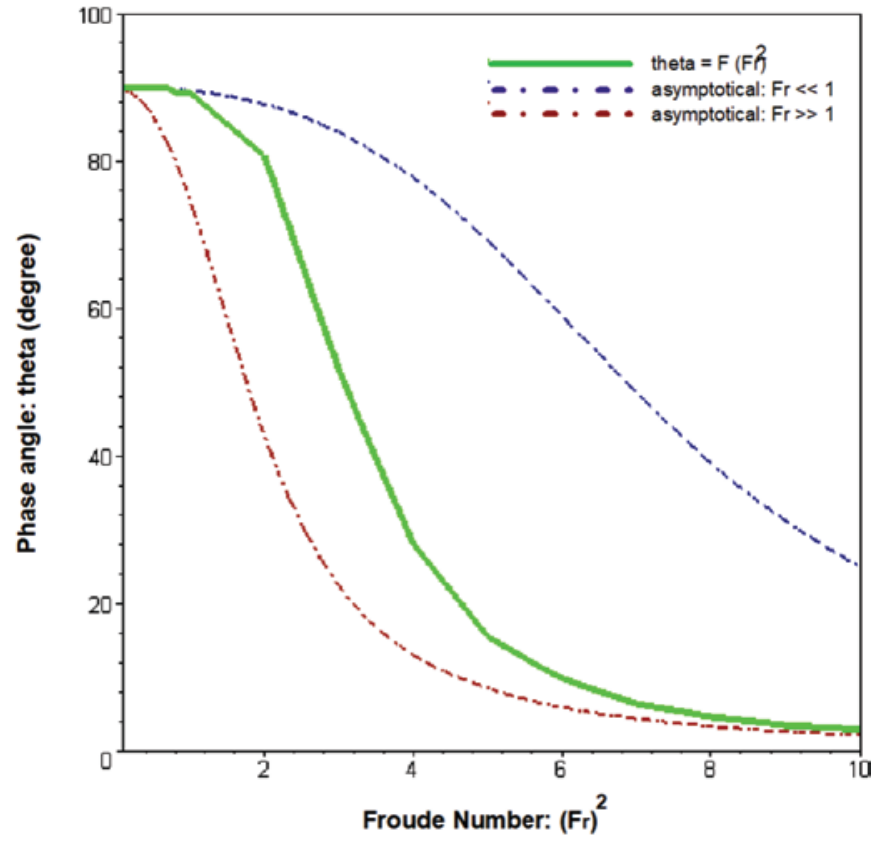

Figure 8

Phase angle of the dimensionless hydrodynamic force on the face of the dam

and generated due to the dam vibration at the interface of a semi-infinite fluid domain reservoir, results in an exact expression for the field of hydrodynamic pressures.

2) Through the hydrodynamic pressure in the complex form, the force that the fluid exerted on the face of the dam was obtained, finding the conservative effects that translate the inertial aspects of the interaction dam-reservoir, and the dissipative effects that translate the aspects of damping (free surface waves) in the dam-reservoir interaction.

3) The conservative and dissipative effects of the reservoir on the dam, respectively, increase and decrease, with the growth of the Froude number.

4) The intersection point of the curves in the graph of Figure 2, corresponds to the Froude number that makes the real part (conservative effects) equal to the imaginary part (dissipative effects).

5) For extreme values of the Froude number, asymptotic solutions can easily be used to determine characteristic parameters which evidence the inertial and damping aspects of the dam-reservoir system.

6) The non-reflection of free surface waves at infinity, in a semiinfinite, incompressible and non-viscous fluid medium, is responsible for the dissipation of the system energy if the vibrating structure is "in the vicinity" of the free surface.

\section{Acknowledgements}

The authors are grateful to Federal University of Brasilia (UnB/ PECC), Federal University of Pará (UFPa/FEC) and National Council for the Improvement of Higher Education (CAPES) for the financial resources (grants) received for this work. 


\section{References}

[1] AYDIN, I. and DEMIREL, E. Hydrodynamic modeling of damreservoir response during earthquakes. Journal of engineering mechanics asce/february 167. 2012.

[2] AZEVEDO, J. P. S. Application of the boundary element method to two-dimensional nonlinear gravity wave problems, $\mathrm{PhD}$. Thesis, Computational Mechanics Institute, Southampton, Inglaterra, 1991.

[3] BOUAANANI, N. and LU, F. Y. Assessment of potential-based fluid finite elements for seismic analysis of dam-reservoir systems. Computers and Structures 87: 206-224. 2009.

[4] CHAKRABARTI, P. and CHOPRA, A. K. Hydrodynamic effects in earthquake response of gravity dams. A.S.C.E., J. Struct. Div. 100, 121-1224, 1974.

[5] GIBERT, R. J. Virations des structures: interactions avec les fluides sources d'excitation aléatoires. Eyrolles, Paris, 1988.

[6] GOGOI, I. and MAITY, D. A non-reflecting boundary condition for the finite element modeling of infinite reservoir with layered sediment. Advances in Water Resources 29 1515-1527. 2006.

[7] KÜÇÜKARSLAN, S. 16th ASCE Engineering Mechanics Conference. July 16-18, University of Washington, Seattle. 2003.

[8] LAMB, H. Hydrodinamics, 6th Ed. Dover, New York. 1945.

[9] LI, S. M. Diagonalization procedure for scaled boundary finite element method in modeling semi-infinite reservoir with uniform cross-section. International journal for numerical methods in engineering. 80: 596-608. 2009.

[10] MENDES, N.B. A wave propagation study and application of the seismo in the coupled dynamical analysis arc dam-reservoir-foundation. (Doctoral thesis) (In Portuguese). Federal University of Brasilia (UnB/PECC), Brasília-DF-Brazil. 2018.

[11] PARRINELLO, F. and BORINO, G. Lagrangian finite element modelling of dam-fluid interaction: Accurate absorbing boundary conditions. Computers and Structures 85 932-943. 2007.

[12] PEDROSO, L. J. Alguns aspectos da interação fluido-estrutura em estruturas off-shore. Dissertação de Mestrado. COPPE/UFRJ, Rio de Janeiro, pp. 338. 1982.

[13] SANCHO, F. E. P. Texto de apoio de hidráulica fluvial e marítima. III - Hidráulica dos escoamentos em canais de leito fixo. Departamento de Engenharia Civil, Faculdade de Ciência e Tecnologia, Universidade de Coimbra. 1982.

[14] SHARAN, S. K. Finite element analysis of unbounded and incompressible fluid domains. International Journal for $\mathrm{Nu}$ merical Methods in Engineering, vol. 21, 1659-1669. 1985.

[15] SILVA, S. F. \& PEDROSO, L. J. Interação barragem-reservatório no domínio infinito de fluido incompressível. Relatório Técnico de Pesquisa. RTP-UnB/ENC. Brasília. 2005.

[16] SILVA, S. F. Dynamic interaction dam-reservoir: analytical and numerical models. (Doctoral thesis) (In Portuguese). Federal University of Brasilia (UnB/PECC), Brasília-DF-Brazil. 2007.

[17] TRINDADE, P. I. C. Simulação da propagação de ondas em canais pelo método dos elementos de contorno. Dissertação de Mestrado. COPPE/UFRJ, Rio de Janeiro. 2003.

[18] WESTERGAARD, H. M. Water pressures on dams during earthquakes. Transactions A.S.C.E. 98, 418-472. 1933. 